\title{
Assuring project quality: The importance of enhancing contract documents
}

\author{
N.D. Gunawardena
}

\begin{abstract}
This paper evaluates the ability of two selected Contract Documents presently used in the Sri Lankan construction industry, namely Conditions of Contracts and Specifications, to assure project quality. The evaluation is based on five fundamental concepts that are common to both quality and project management. The results show that the ICTAD Conditions of Contract need to be enhanced by adding new clauses to assure quality which is a critical component to the successful management of construction projects; particularly, a requirement to institute a quality assurance system for the project in accordance with ISO seems to be the most appropriate for this purpose. The document could be further enhanced to incorporate other requirements such as health and safety and environmental protection as well. It is also found, based on recent studies, that the Specifications used in the industry should be improved to assure construction quality. The areas that need significant improvement according to contractors include 7 materials and 12 work items in the document; eventually, however, the entire document should be revised in the light of changes in technology and materials used for construction work over the last several years.
\end{abstract}

\section{Introduction}

Construction projects are usually carried out as contracts. The client and the contractor are the two parties to a construction contract, which usually follows one of the standard forms of contract in common use in the industry. Traditionally, contract documents have been used for defining client's requirements in terms of specifications, contract data and construction drawings; making payments to the contractor as per the $B O Q$; and administration of the contract in accordance with the conditions of contract (Ashford, 1989). There are many standard forms of contract, which have been introduced by organisations such as the International Federation of Consulting Engineers (FIDIC 1999), Institute of Civil Engineers (ICE, 1993) and the World Bank (1995), used in many countries for both international competitive bidding (ICB) and local competitive bidding (LCB). In Sri Lanka, LCB contracts are mainly based on the Standard Bidding Documents published by the Institute for Construction Training and Development (ICTAD).

The client may be considered as the main stakeholder of a construction project, but he is not the only one; other parties such as regulatory bodies, local authorities, utility organisations, subcontractors, end users, sponsors, environmentalists, and the public at large are also important stakeholders.

The objective of Project Management is to meet or exceed the needs and expectations of these stakeholders through the application of knowledge, skills, tools and techniques to project activities (PMI, 1996). This involves balancing competing demands among scope, time, cost and quality objectives of the project; and managing stakeholders with differing needs and expectations.
In Sri Lanka, construction project managers often use Contract Documents as the basis or the reference for meeting the project objectives or requirements. However, the ability of Contract Documents, in their present form, to provide an effective framework for Project Management has not yet been properly evaluated. The main objective of this study, therefore, was to evaluate the Contract Documents, frequently used in Sri Lanka, in relation to some important aspects of Project Management and identify the need to enhance them.

The evaluation presented in this paper is based on the five fundamental concepts that are common to both quality and project management (ISO 10006, 1997; PMI, 1996); wherever possible, the issues that come up in the process are appropriately discussed with the findings of research studies undertaken both in Sri Lanka and other countries.

\section{The Fundamental Concepts of Quality}

Quality management complements project management (PMI, 1996). It is possible to identify similarities between both project and quality management as both disciplines recognise the importance of following concepts with respect to projects (ISO 10006, 1997; Hides et al., 2000):

(a) Satisfaction of customer and other stakeholders needs;

(b) Project to be carried out as a set of planned and interdependent processes;

(c) Focussing on the quality of processes as well as products; 
(d) Management is responsible for creating an environment for quality; and

(e) Management is responsible for continual improvement.

All these five quality concepts should be applied in the journey towards quality project management (Bryde, 1997). They constantly underpin the project management process; although in a given phase of the project one concept may be more highlighted than another.

Therefore, the above concepts can be considered as Critical Success Factors for any project. In the following sections, they are used for evaluating the ability of Contract Documents, presently used in the Sri Lankan construction industry, to assure project quality in an effective manner.

\section{Evaluation of Contract Documents in relation to Fundamental Concepts of Quality}

\subsection{Satisfaction of Customer and other Stakeholder needs}

All the five quality concepts are generally considered to be equally important, but the emphasis on stakeholders is more fundamental to project management. Managing stakeholders requires a clear procedure with number of discrete stages (Maylor, 1998):

(a) Identification of all potential stakeholders;

(b) Determination of their requirements (needs and expectations) from the project;

(c) Setting project objectives in line with the stakeholder requirements; and

(d) Ensuring that all stakeholders know that the project has been a success when it is completed.

The Contract Documents do not identify any stakeholder other than the client and do not identify their needs, as required in the above procedure. They, however, provide the requirements of the client with respect to time, cost and product characteristics.

While time and cost aspects of a project are important it is only the product characteristics that determine the performance of the end product; they are usually communicated to the contractor through Contract Data, Drawings and Specifications. Although no study has been undertaken in the past in Sri Lanka to identify quality related problems of Contract Data or Drawings, studies in other countries reveal some of their shortcomings. Inaccurate and ambiguous drawings which contain conflicting and inadequate references often lead to construction errors and defects (BRE, 1982; Assaf et al., 1995). As for the Specifications, it has been found that those published by ICTAD are used in most of the construction contracts in Sri Lanka; however, both consultants and contractors agree on the problem of their inadequacy (Dayaratne et al, 2002). This can have serious implications on the quality of construction as deficient specifications are one of the most misunderstood aspects in contract administration (Thomas et al., 1995).

In project management, it is not sufficient to understand the stakeholder needs; the project team must also ensure that all project activities focus on and are capable of meeting these needs. In this respect, very little guidance is provided by the Contract Documents. The Conditions of Contract (ICTAD, 2002), requires that 'the contractor shall construct and install the work in accordance with the Specifications and Drawings'. In the absence of any clear procedures stated in Contract Documents that specify how to carry out project activities, the degree to which customer needs are met would be, to a greater extent, dependent on the existing quality practices of the contractor. Also, the above condition makes the situation more difficult for the contractor to use better specifications than those stated in the Contract Documents.

The Conditions of Contract (ICTAD, 2002), however, provide for another important aspect: stakeholder feedback. This is an important provision as it is necessary to obtain feedback from all stakeholders as appropriate throughout the project (ISO 10006, 1997). This issue is party addressed by ICTAD Conditions of Contract in clause 31 - 'Management Meetings' ; the scope, however, is limited to review of plans for remaining work and early warning given by the contractor on matters related to future events or circumstances that may adversely affect quality of the work, contract price (cost) or project duration. The areas that have not been addressed include conflict resolution between different stakeholder needs and changing of these needs. Particularly, to address changing stakeholder needs, including those of new stakeholders, there must be a proper procedure within Contract Documents.

Finally, it should be noted that the Contract Documents used in many LCB contracts are unable to address the above issues as they do not have a requirement similar to the 'Contract Review' requirement given in ISO 9001(1994) or the 'Customer related Processes' in ISO 9001(2000) quality standards.

\subsection{Project to be carried out as a set of planned and independent processes}

Under this quality concept, it is required to identify and document the project processes and those who carry out them together with their responsibilities and authorities. In quality management, this requirement is termed as 'Quality Planning', which includes preparation of a Project Quality Plan. The quality plan should describe how the project team would achieve quality objectives of the project. In quality terminology, it should describe the project quality system: 'the 
organisational structure, responsibilities, procedures, processes and resources needed to implement quality management' (ISO 9001, 1994). The main purpose of such a system is to direct and control project management teams with regards to quality. In planning the project quality system the project management team should (ISO 9001, 2000):

(a) Identify the processes needed for the quality system and their application throughout the project;

(b) Determine the sequence and interaction of these processes;

(c) Determine criteria and methods needed to ensure that both the operation and control of these processes are effective;

(d) Ensure the availability of resources and information necessary to support the operation and monitoring of these processes;

(e) Monitor, measure and analyse these processes; and

(f) Implement actions necessary to achieve planned results and continual improvement of these processes.

As it would be seen from the description given above the project quality plan is a document setting out the specific quality activities and resources pertaining to a particular contract or project.

The Conditions of Contract (ICTAD, 2002) define general responsibilities and authorities of main stakeholders of the project: the contractor, the client and the consultant. However, none of these are related to any specific project processes. The control Contract Documents have over identification and documenting the processes, is limited to preparation of a programme showing the general methods, arrangements, order, and timing for all the activities in the works. This requirement being too general and given under the time control section (Clause 27) of the Conditions of Contract (ICTAD, 2002), is likely to limit responsibility of the contractor only to produce some form of time schedule such as a bar chart or network diagram.

\subsection{Focus on the Quality of Both Processes and Products}

Focusing on product quality is the emphasis of the 'quality control' approach; whereas, process quality is a feature of 'quality assurance' which is the approach used in the internationally recognised ISO 9000 series of standards. The importance of prevention over inspection - avoiding mistakes rather than correcting them later - is the objective of focusing on process quality (PMI, 1996).

The underlying principle of emphasising on process quality is to standardise the processes so that wellmanaged processes may be realised organisation-wide and over future projects. This way (with proper 'Process Control'), the contractors could produce work with consistent characteristics in almost all project processes; control any processes that result in nonconforming works; and continuously improve them to produce better works. Those who concentrate only on the outcome of the processes would have no clue as how to prevent nonconforming works or to improve their quality.

Of all Contract Documents, the Specifications, Drawings, Contract Data and Conditions of Contract are related to project quality; that too, however, is mainly limited to product quality. The study, undertaken to analyse the quality issues addressed by Contract Documents by Nismy (2003), clearly indicated their limitations. According to the study, Specifications mainly address issues relating to product quality, whereas process quality is limited to few items; Conditions of Contract briefly describe some 'quality control' requirements; and Drawings, for obvious reasons, only describe the physical features of the intermediate and final products.

The situation is much different in contracts based on FIDIC documents where, the Conditions of Contract (FIDIC, 1999) clearly specify under Clause 4.9, the need for a quality assurance system instituted by the contractor, which should have documented procedures describing how quality should be achieved in respect of all project processes.

\subsection{Management is responsible for creating an environment for quality}

Creating an environment for quality includes (ISO 10006 , 1997):

(a) Providing a project structure and support conducive to meeting project objectives;

(b) Making decisions based on data and factual information;

(c) Providing for progress evaluations and using them for quality;

(d) Involving all project personnel in achieving process and product quality; and

(e) Establishing mutually beneficial relationships with subcontractors and suppliers.

The above elements are briefly described below.

\section{Project Structure and Support:}

The management is responsible for establishing the unity of purpose and direction of the project organisation. The top management must take the initiative and lead by example; credibility is extremely important in this respect. The project manager must lead his team rather than becoming just a manager. Such a leadership involves:

- Establishing clear project objectives

- Providing people with the required resources, training, and freedom to act with responsibility and accountability

- Establishing trust and eliminating fear

- Inspiring, encouraging, and recognising people's contributions 
Decisions Based on Data and Factual Information: 'Statistical Techniques' provide essential problem solving tools in the quality management effort (Burati Jr. et al, 1992). The project managers must use them for identification of root causes of quality problems: analysing trends in work processes; and making decisions based on data and factual information rather than on intuition.

\section{Progress Evaluation:}

Progress evaluation activities such as 'Management Review' and 'Quality Audits' are important to identify quality deficiencies before they become major problems. Particularly, quality audits notify the project team of deficiencies and then lead to correction and prevention (Hayden Jr. 1996).

\section{Involvement of All Personnel:}

There can be only little initiative for employees to participate in quality improvement efforts if they are not given the opportunity to plan and perform their own work assignments (Hides et al, 2000). Such an empowerment can increase joy in work and pride in the outcome for all employees (Deming, 1993); which is a sure way of assuring company-wide employee involvement in the quality management process. For empowerment of employees to happen, however, there should be effective and sustained training for the enhancement of their selfesteem and capability to solve problems and to make low-risk decisions (Hayes, 1994; Irani et al., 1997).

Mutually Beneficial Relationships with Suppliers and Subcontractors:

The quality of works is directly related not only to the quality of the drawings and specifications of the consultant, but also to the quality of materials supplied by the vendors, and the quality of the work performed by the sub contractors (Burati Jr. et al, 1992). Although low quality of materials and incompetent sub contractors are market related factors that are beyond contracts' control, close and long-term relationships with them can lead to improved quality of the works.

Unfortunately, none of the Contract Documents used in local projects address the issue of the contractor's responsibility in creating an environment suitable for quality. The Conditions of Contract (ICTAD, 2002), the most likely document to have such a requirement, remain more or less silent about this matter; the guidance is limited only to provision of key personnel (Clause- 9), co-operating and sharing the site with other contractors (Clause - 8), and Management Meeting (Clause -31).

\subsection{Management is responsible for continual improvement of project processes}

This can happen within a project and from one project to another (Maylor, 1998). For learning to take place in a contractor organisation, there need to be processes and structures in place to help create new knowledge, so that employees can improve both themselves and the organisation (Love et al., 2000). But, for obvious reasons, it is not the client's interest to see that this happens unless he gets some benefit out of such improvement. If improvement takes place within the project certainly the client is benefited; for this, it is necessary to implement processes such as 'Corrective and Preventive Action', 'Quality Audits', and 'Management Review' (ISO 9001, 1994; Hayden Jr, 1996)

The improvement process within a project can be clearly explained using the Plan-Do-Check-Act (PDCA) cycle as given below.

Plan - determining the process necessary to deliver the output (product) in accordance with quality requirements

Do- implementing the process

Check - monitoring and measuring the process and output against quality requirements and reporting results

Act - taking action to improve the process.

Improvement from one project to another is long-term in nature. As the improvements are not immediate, there is a need for documenting lessons learned from past projects to be used for future projects. This long term continual improvement is not encouraged by Contract Documents used in the Sri Lankan construction industry. However, such a practice could indirectly benefit the whole industry, although the direct benefit would be to the contractor. In order for this to happen, the contractor should collect data and factual information on project activities. 'Quality Records' such as data and information on nonconformities or failures certainly are useful in preventing them in order to improve the construction processes (Abdul-Rahman, 1995). It is, however, not possible to stipulate in Conditions of Contract to collect data for long-term improvement of contractor organisations; yet, a requirement to institute a quality assurance system for the project would certainly put the necessary structure and processes in place to record experience, learn from the present and past projects, and improve performance of the future projects.

\section{Enhancing Contract Documents}

The suggestions made in this section are limited to the Specifications and the Conditions of Contract, although they are only two of the Contract Documents that directly affect project quality. Other documents, namely the Drawings, Contract Data, and Bill of Quantities directly affect quality; yet, no specific suggestions are made here as they were not discussed in detail in the previous sections due to their project specific nature. Whereas, documents such as the Agreement, Letter of Acceptance, and Contractors Bid may not have any direct affect on quality of the works. 


\subsection{Specifications}

The requirement for enhancing the Specifications is mainly based on the study carried out by Nismy (2003). The study has identified 7 materials and 12 work items that require to be significantly improved in ICTAD Specifications for Building Works to assure quality of construction work. These items are listed in Table 1.

Table 1: Items of Specifications Requiring Significant Improvement

\begin{tabular}{|l|l|}
\hline \multicolumn{1}{|c|}{ Materials } & Work items \\
\hline $\begin{array}{l}\text { Glazed ceramic tiles and } \\
\text { specials }\end{array}$ & Painting \\
\hline Painting-Paints, Oil, Varnishes. & Plastering \\
\hline Steel reinforcement & Aluminium work \\
\hline Water proofing materials & Concrete \\
\hline Lime & Form work \\
\hline Timber for formwork & Filling under floor \\
\hline Cement & Lime-Cement-Sand \\
& Mortar \\
\hline & Ironmongery \\
\hline & Damp proof course \\
\hline & Rain water pipes \\
\hline & Scaffolding \\
\hline & Site work \\
\hline
\end{tabular}

The results were obtained from a random sample of 29 contractors and tested for statistical significance (at alpha $=5 \%$ ); yet individually some contractors may not agree with the items in the above table. Such individual differences are possible as the above results represent the views of all the contractors in the industry as a whole. Further, the views of consultants could also be different from the above. Despite such differences that may arise in a much detailed analysis of ICTAD Specifications, the author is of the view that it is high time the construction industry seriously considered their adequacy in the light of changes in technology and materials over the last seventeen years or so. This view is also supported by another study (Dayaratne et al., 2002); according to which, the majority of consultants and contractors 'agree' or 'strongly agree' on the inadequacy of Specifications used in the industry.

It is, therefore, advisable to look at all items in the ICTAD Specifications for Building Works for possible improvements. Improving all items would require considerable amounts of time and effort. An effective way of doing this would be to start with items requiring significant improvement, such as those given in Table 1 , and then move in to other items in the order of importance or significance.

\subsection{Conditions of Contract}

The discussion presented in the previous sections suggests that ICTAD Conditions of Contract (2002) could be further enhanced to overcome certain problems in assuring project quality. The areas which need to be addressed in Conditions of Contract include:

(a) Contract Review - to clearly understand the requirements of the stakeholders, but not limited to those of the client; to obtain customer feedback as the project progresses; and to efficiently and effectively handle changes in stakeholder needs.

(b) Quality Planning - to draw a proper project quality plan to describe how project objectives are expressed in terms of time, cost and product characteristics, which include the project structure, responsibilities, procedures, processes and recourses.

(c) Process Control - to assure process quality in addition to product quality ; this is a significant shift from the 'quality control' approach described in the Contract Documents which depend a lot on 'Inspection and Testing' activities.

(d) Requirements for (i) Statistical Techniques; (ii) Correction and preventive action; (iii) training; (iv) control of supplier and sub contractor quality; ( $v$ ) health and safety; and (vi) environmental protection.

It should be noted that most of the above aspects could be addressed adequately, if a quality assurance clause is added to the Conditions of Contract. FIDIC (1999) document has included a specific clause as given below:

'The Contractor shall institute a [documented] quality assurance system to demonstrate compliance with the requirements of the Contract .....'

A quality assurance system to ISO 9000 seems to be the most appropriate for this purpose. A recent study revealed that the Contractors agreed that documented procedures to control site activities would be beneficial to improve their performance (Karunaratne, 2003). The areas other than those in ISO 9000 quality assurance system required from contractors according to this study included health and safety and environment protection. Therefore, inclusion of additional clauses in the Conditions of Contract to cover these areas would enhance the document to a greater extent.

\section{Conclusions}

The fundamental quality concepts cannot be separated from the principles of project management. Evaluation of Contract Documents used in the Sri Lankan construction industry in relation to these quality principles revealed that there is a need for enhancing 
the Specifications and the Conditions of Contract for assuring project quality. However, no suggestions are made with respect to other contract documents such as Drawings, Bills of Quantities, and Contract Data, although they, too, affect quality.

According to recent studies, improvements are needed in the Specifications for Building Works with respect to some materials and work items. Although there can be differences of opinion as to which items of the Specifications need significant improvement, the author is of the view that it is high time the construction industry seriously considered the adequacy of the ICTAD Specifications in the light of changes in technology and materials used for construction work over the last several years. Therefore, it is advisable to revise the whole document; an effective way of doing this would be to start with items requiring significant improvement and then move in to other items in the order of importance or significance.

The Contract Documents, in their current form, emphasise only on 'quality control' of construction work. Therefore, the inclusion of 'quality assurance' clauses in the Conditions of Contract can significantly improve construction quality. Additional clauses, however, are also needed to cover stakeholder needs with respect to health and safety and environment protection. As this is a fundamental shift in contract procedure, there can be difficulties initially, but one overriding fact remains: quality assurance is a critical component to the successful management of construction projects.

\section{References}

Abdul-Rahman, H. (1995), Improving Construction Performance with Non-conformance Information, First International Conference on Construction Project Management, January 1995, Singapore, 465-477.

Ashford, J.L. (1989), The Management of Quality in Construction, E. \& FN Spon, London.

Assat, S., Al-Hammad, A. and Al-Shihah, M. (1995), The Effect of Faulty Construction on Building Maintenance, Building Research and Information, 23 (3), 175-181.

BRE (1982), Quality in Traditional Housing, Building Research Establishment, HMSO, London.

Bryde, D.J. (1997), Underpinning Modern Project Management with TQM Principles, The TQM Magazine, 9 (3), 231-238.

Burati Jr., J.L., Matthews, M.F., and Kalidindi, S.N. (1992), Quality Management Organisations and Techniques, Journal of Construction Engineering and Management, 118(1), 112-128.
Dayaratne, M.P.C.J., Alaglyawanna, A.M.A.K. and Tennakoon, N.P. (2002), Quality of Specifications used in Building Construction, Final Year Project Report, Department of Civil Engineering, University of Moratuwa.

Deming, W.E. (1993), The New Economics, Massachusetts Institute of Technology, Cambridge, Massachusetts.

FIDIC (1999), Conditions of Contract for Construction, International Federation of Consulting Engineers.

Hayden Jr. W. M. (1996), Connecting Random Acts of Quality: Global System Standard, Journal of Management in Engineering, 12 (3), 34-44.

Hayes, B.E. (1994), How to Measure Empowerment, Quality Progress, 27 (2), 41-46.

Hides, M.T., Irani, Z., Polychonakis, I., and Sharp, J. M. (2000), Facilitating Total Quality through Effective Project Management, International Journal of Quality \& Reliability Management, 17 (4/5), 407-422.

ICTAD (2002), Conditions of Contract, Institute for Construction Training and Development, Sri Lanka.

ICE (1993), The New Engineering Contract, The Institute of Civil Engineers, London.

Irani, Z., Sharp, J.M. and Kagioglou, M. (1997), Improving Business Performance through Developing a Corporate Culture, The TQM Magazine, 9 (3), 206-216.

ISO 9001 (1994), Quality Systems - Model for Quality Assurance in Design, Development, Production, Installation, and Servicing, International Organisation for Standardisation, Stockholm.

ISO 9001 (2000), Quality Systems -Requirements, International Organisation for Standardisation, Stockholm.

ISO 10006 (1997). Quality Management - Guidelines for Quality in Project Management, Intemational Organisation for Standardisation, Geneva.

Karunaratne, C.D. (2003), The Importance and Usage of Documented Procedures in Construction Contracts, M.Sc. Progress Review Report, University of Moratuwa, Moratuwa. 
Love, P.E.D., Heng, L., Irani, $Z$ and Faniran, $O$. (2000), Total Quality Management and the Learning Organisation: A Dialogue for Change in Construction, Construction Management and Economics, 18, 321-331.

Maylor, H. (1998), Business Project ManagementThe Primer, UHL International, Hull.

Nismy, R.M. (2003), Impact of Contract Documents on Quality Management Aspects in Building Construction Industry of Sri Lanka, M.Sc. Progress Review Report, University of Moratuwa, Moratuwa.
PMI Standing Committee (1996), A Guide to the Project Management Body of Knowledge, Project Management Institute, PA, USA.

Thomas, H.R., Smith, G.R. and Wirsching, S.M. (1995), Understanding Defective Specifications, Journal of Construction Engineering and Management, 121(1), 55-65.

World Bank (1995), Standard Bidding Documents Procurement of Small Works (Smaller Contracts), The World Bank, Washington, D.C. 